\title{
NKX2.1-Related Disorders: a novel mutation with mild clinical presentation
}

\author{
Sara Monti ${ }^{1}$, Annalisa Nicoletti ${ }^{1}$, Antonella Cantasano ${ }^{1}$, Heiko Krude ${ }^{2}$ and Alessandra Cassio ${ }^{1,3^{*}}$
}

\begin{abstract}
Background: A highly variable phenotype characterized by thyroid, respiratory and neurological defects has been reported in an already established group of disorders namely NKX2.1-related disorders. We describe here the case of an infant with a novel mutation of the NKX2.1 gene characterized by mild clinical presentation. Aim of the study was to elucidate the genotype-phenotype correlation in our patient.

Methods: We performed genetic analysis of the NKX2.1 gene in an infant with no neonatal respiratory distress and near-normal results at neonatal screening test for congenital hypothyroidism, choreoathetosis, ataxia and delayed independent walking.

Results: A novel mutation of the NKX2.1 gene has been identified, that is responsible for a mild framework of congenital hypothyroidism and neurological symptoms.

Conclusions: The frequency of congenital hypothyroidism cases associated with NKX2.1 mutations is expected to be higher in a subgroup of patients, selected according to the neurological presentation. In these patients the analysis of NKX2.1 mutational status is recommended.
\end{abstract}

Keywords: NKX2.1-related disorders, Syndromic hypothyroidism, Neonatal screening, Choreoathetosis

\section{Background}

The management of the classical form of congenital hypothyroidism $(\mathrm{CH})$ has changed thanks to the introduction of neonatal screening programs, which allow early diagnosis and replacement therapy. Over the last few years the progressive reduction of TSH-cutoff at neonatal screening and the advancements in the molecular analysis led to the definition of novel syndromic forms of $\mathrm{CH}$, that are associated with mild thyroid deficiency [1].

Mutations of the $N K X 2.1$ gene, previously known as TTF1 (thyroid transcription factor 1, OMIM*600635), mapping on chromosome 14q13, have been identified and associated with a syndromic form of $\mathrm{CH}\left(\mathrm{OMIM}^{* 610978)}\right.$ [2], initially named brain-lung-thyroid syndrome [3] due to the broad phenotypic spectrum including a variable combination of lung, thyroid and neurological defects.

\footnotetext{
* Correspondence: alessandra.cassio@unibo.it

${ }^{1}$ Department of Medical and Surgical Sciences, Pediatric Unit, University of

Bologna, Bologna, Italy

${ }^{3}$ Policlinico S.Orsola- Malpighi, U.O. Pediatria, Via Massarenti 9, 40138

Bologna, BO, Italy

Full list of author information is available at the end of the article
}

Recently, in light of the varied manifestations of heterozygous mutations of the $N K X 2.1$ gene, the disorders have been referred to as NKX2.1-related disorders [4]. These disorders range from benign hereditary chorea $(\mathrm{BHC})$, the hallmark of NKX2.1-related disorders, to choreoathetosis, congenital hypothyroidism and neonatal respiratory distress [5-13].

So far, ninety-six mutations of the NKX2.1 gene have been reported, 70 of which are point mutations and 26 large deletions, often spanning the entire gene (HGMD Professional 2014.2).

The NKX2.1 gene has three exons and encodes for a member of the NK-2 family of transcription factors [14] that mediates thyroid-specific genes transcription. During embryogenesis the gene is expressed in the thyroid gland, in the lung and in the forebrain, especially in the hypothalamic area, infundibulum and basal ganglia region [15-17].

We identified a novel mutation of NKX2.1 in an infant showing neurological symptoms associated with nearnormal results at $\mathrm{CH}$ screening test, negative history of neonatal respiratory distress and recurrent pulmonary diseases. 


\section{Case presentation}

Child of non consanguineous parents, the patient was born at 41 weeks of normal pregnancy, with normal birth weight $(3965 \mathrm{~g})$. The family history reported two cases of walking delay in the paternal line and several cases of autoimmune thyroid diseases in the maternal line. Both parents showed normal thyroid function. Neonatal adaptation was normal (APGAR $1^{\circ} 9,5^{\circ} 10$ ), with no respiratory distress at birth. At neonatal screening, TSH spot value was equal to the cut-off level $(10 \mathrm{mUI} / \mathrm{L})$. The test was repeated on blood spot and TSH levels became normal $(4.4 \mathrm{mUI} / \mathrm{L})$, thus no further analysis was performed. In the first months of life, the infant showed a progressive impairment in neurological development, characterized by choreoathetosic movements, disordered motility in the lower limbs, reduced motility of the upper limbs, axial hypotonia and development delay. At 8 months of age the analysis revealed a mild hypertireotropinemia with normal fT4 values. Thyroid ultrasound showed a normal in situ gland. Electroencephalography and brain MRI were normal at 12 months of age. Due to the progressive increase of TSH levels, the infant started the replacement therapy with L- Thyroxin at 13 months. Growth parameters and pulse rate were recorded, electrocardiography was performed and blood samples were taken in order to determine TSH and free T4 serum levels. Biochemical and clinical features measured at follow-up are reported in Table 1.

Serum free T4 and TSH levels were measured using a commercial chemiluminescent assay (Bayer, Fenwald, Germany). The clinical manifestation of the patient resembled defects that have been previously associated with mutations of the NKX2.1 gene. Therefore, DNA sequencing analysis was performed after obtaining informed consent. Genomic DNA was extracted from peripheral blood leukocytes of the child and his parents and the NKX2.1 gene coding region, comprising exon 1-3 of isoform 1, as well as the exon-intron boundaries were amplified by PCR and directly sequenced by Sanger sequencing.

Two point mutations were identified, a heterozygous substitution, NM_001079668:c.390C > G:p.(Tyr130Term), resulting in a nonsense mutation and a single base exchange in intron 2, NM_ 001079668:c.463 + 41C > T, not reported in the SNP database (NCBI).
The mutation was not detected in the parents, as shown in Fig. 1. Upon administration of the replacement therapy, the patient showed a progressive improvement in neuromotor and growth development. Of note, the height increased from -0,63 SDS to -0,12 SDS after one year of treatment.

\section{Discussion}

We report the case of an infant with a novel mutation of the NKX2.1 gene, showing neurological symptoms, with mild impairment of thyroid function, in the absence of neonatal respiratory distress, as a typical example of an already established group of disorders namely NKX2.1related disorders.

The phenotypic spectrum of NKX2.1-related disorders is highly variable and ranges from abnormalities in a single organ system to any combination of brain, thyroid and lung involvement. The neurological presentation may be the most frequent one. In particular $\mathrm{BHC}$, the hallmark of NKX2.1-related disorders, is a classic early finding, as suggested by previous evidence [5], and is characterized by involuntary, irregular, jerk-like and continuous movements, frequently associated with hypotonia, ataxia and choreoathetosis. In some cases BHC is associated with respiratory distress syndrome or congenital hypothyroidism.

The case that we report here is characterized by mild clinical presentation. The movement disorders of the child were monitored starting from the first months of life and choreathetosis was evident at 8 months. Neonatal $\mathrm{CH}$ screening showed near-normal results. A mild form of hypothyroidism was detected in his first months of life and was responsive to a low dose of L-Thyroxine. No respiratory distress at birth and no respiratory symptoms during childhood were observed.

A novel NKX2.1 nonsense mutation (Y130X) and a single base exchange in intron 2 (c. $463+41 \mathrm{C}>\mathrm{T}$ ), not reported in the SNP database (NCBI), were identified. The mutations were not detected in parents, despite the known history of walking delay in the paternal line. This evidence indicates that we identified de novo mutations.

The phenotype observed in our patient was mild despite the presence of $N K X 2.1$ gene null mutation (Y130X). This discrepancy is not surprising in light of previous data

Table 1 Patient's laboratoristic and neurological features before treatment with L-thyroxine

\begin{tabular}{|c|c|c|c|c|}
\hline & 4th day & 10th day & 8th month & 13th month \\
\hline TSH spot value (mUl/L) & 10 & 4.4 & & \\
\hline TSH serum value (Normal range in our laboratory: $0.5-5 \mathrm{mUI} / \mathrm{L}$ ) & & & 8.8 & 13.8 \\
\hline fT4 serum value (Normal range in our laboratory: $10.5-22 \mathrm{pmol} / \mathrm{L}$ ) & & & 14.8 & 13.4 \\
\hline Choreoathetosis & - & - & +- & ++ \\
\hline
\end{tabular}



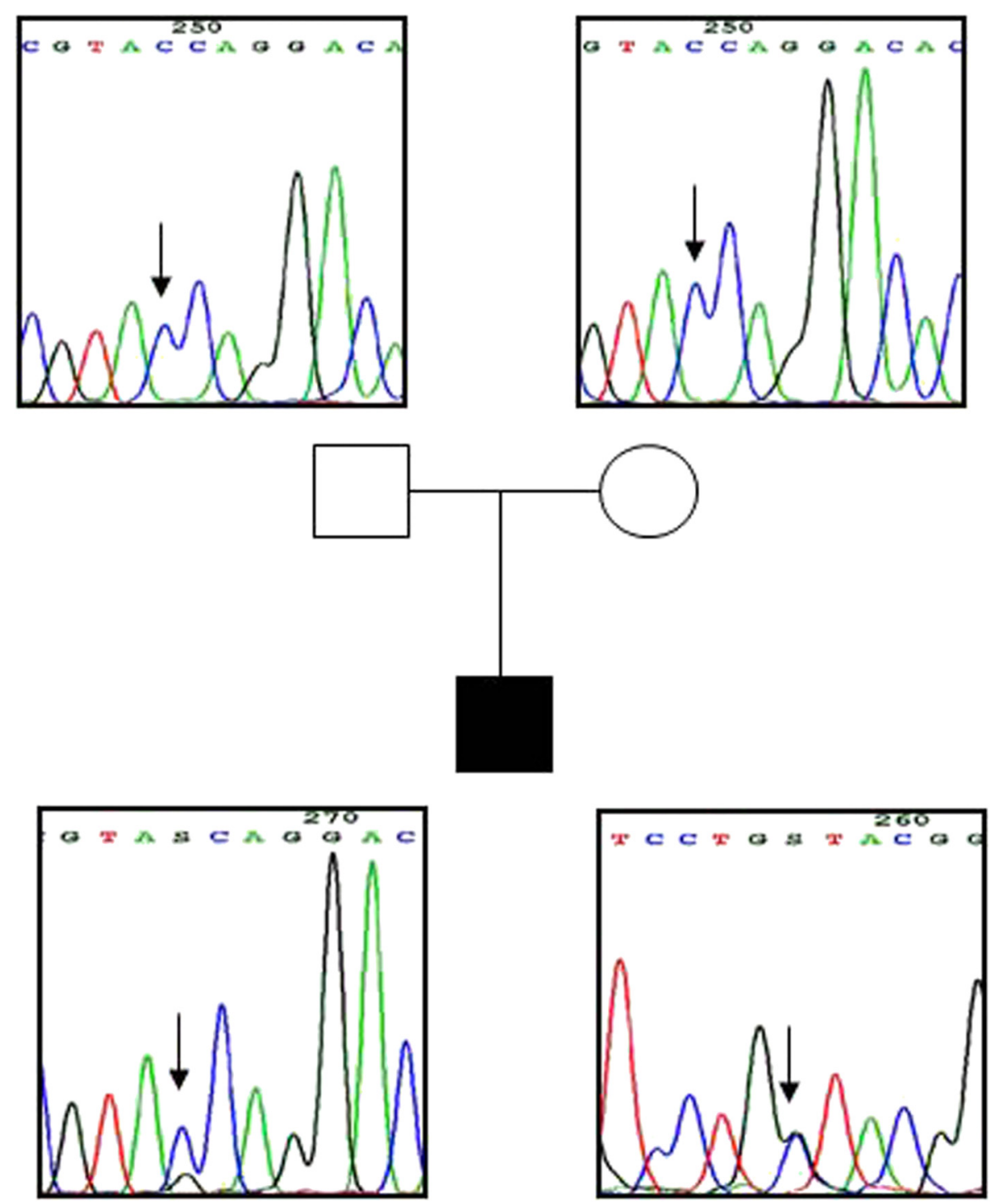

Fig. 1 Chromatograms obtained from the genetic analysis of the patient and of his parents. Family tree with the corresponding chromatograms of NKX2.1 exon 2 showing c.390C > G:p. (Tyr130Term) mutation (arrow): the father and mother are homozygous for the wild-type nucleotide (upper panels, sense strand), the proband is heterozygous for the mutation (bottom panels, sense and antisense strands)

showing the lack of genotype-phenotype correlation in NKX2.1-related disorders $[7,11,18,19]$, likely due to the pathogenetic role of genetic and environmental factors that need to be further investigated [20].

The pathogenetic mechanism of the mutation, as other truncating mutations, might involve haploinsufficiency $[2,8,10,12,21-23]$.

However, we cannot exclude the potential activation of an alternative initiation site leading to a shorter product of 268 aminoacids with intact homeobox domain (HD) and TD and lacking the protein N-terminal. This product may partially preserve the protein function and therefore explain the mild phenotype of the patient.
Several nonsense NKX2.1 mutations upstream to the DNA binding domain, which associate with a high phenotypic variability, have been previously reported $[2,7,22,24-27]$.

Asmus et al. [7], Peall et al. [22] and Hamvas et al. [24] reported three cases characterized by the same Y144X nonsense mutation and different phenotypes. Asmus et al. and Peall et al. reported the case of a patient with chorea, as the only clinical presentation. Hamvas et $a l$. described a patient with hypotonia, development delay and recurrent pulmonary infections, who died of a respiratory sincytial virus infection.

Other nonsense NKX2.1 mutations upstream to the DNA binding domain occuring with choreoathetosis, 
$\mathrm{CH}$ and respiratory distress have been reported by Krude et al. (C117X) [2], Peall et al. (W143X) [22], Ferrara et al. (S175X) [25] and Nakamura et al. (Y98X) [26].

The G142X nonsense mutation upstream to the NKX2.1 DNA binding domain was described by Salerno et al. [27] in a patient with $\mathrm{CH}$ and respiratory distress but not chorea, whose father was a immune carrier.

Nevertheless, the high phenotypic variability, even in cases carrying the same mutation, is not restricted to NKX2.1 nonsense mutations, but is a feature of all types of NKX2.1 mutations.

Therefore, the hypothesis of the activation of an alternative initiation site with intact HD in the novel Y130X nonsense mutation, upstream to the NKX2.1 DNA binding domain, seems to be remote. Functional studies are needed to definitively rule out this hypothesis.

\section{Conclusions}

Previously published data do not allow a clear interpretation of the pathogenetic role of NKX2.1 mutations in NKX2.1-related disorders, since a number of cases were not fully characterized for the phenotypic presentation of choreoathetosis. Moreover, the same mutation of the NKX2.1 gene can present with diverse phenotypes and highly variable clinical manifestations. Our analysis suggests that in the absence of severe thyroid deficit or respiratory distress, neurological evaluation should guide the patient's management. The mild hypothyroidism, frequently observed in these cases, may not be detected by neonatal screening. The low frequency of $\mathrm{CH}$ cases due to $N K X 2.1$ mutations that are reported in literature is expected to be higher in a subgroup of patients selected according to the neurological presentation. In these patients, the analysis of NKX2.1 mutational status is recommended.

\section{Consent}

Written informed consent was obtained from the patient's parents for the publication of this case report and any accompanying images. A copy of the written consent is available for the review by the Editor-in-Chief of this journal.

\section{Abbreviations \\ $\mathrm{CH}$ : Congenital hypothyroidism; BHC: Benign hereditary chorea; HD: Homeobox domain.}

\section{Competing interests}

The authors declare that they have no competing interests.

\section{Authors' contributions}

SM carried out the study design, analysis of data and wrote the report; AN carried out the molecular genetic studies and analysis of data; AC carried out clinical management of patient, collection and analysis of data; HK carried out the molecular genetic studies and revised the manuscript; AC carried out the study conception and design, analysis and interpretation of data, revised the manuscript and coordinated the activities. All authors read and approved the final manuscript.

\section{Author details}

'Department of Medical and Surgical Sciences, Pediatric Unit, University of Bologna, Bologna, Italy. ${ }^{2}$ Institute for Experimental Pediatric Endocrinology, Charité University Medicine, Berlin, Germany. ${ }^{3}$ Policlinico S.Orsola- Malpighi, U.O. Pediatria, Via Massarenti 9, 40138 Bologna, BO, Italy.

Received: 13 January 2015 Accepted: 9 June 2015

Published online: 24 June 2015

\section{References}

1. Montanelli L, Tonacchera M. Genetics and phenomics of hypothyroidism and thyroid dys- and agenesis due to PAX 8 and TTF1 mutations. Mol Cellul Endocrin. 2010;322:64-71.

2. Krude H, Schutz B, Biebermann H, Von Moers A, Schnabel D, Neitzel H, et al. Choreoathetosis, hypothyroidism, and pulmonary alterations due to human NKX2-1 haploinsufficiency. J Clin Invest. 2002;109:475-80.

3. Willemsen MA, Breedveld GJ, Wouda S, Otten BJ, Yntema JL, Lammens M, et al. Brain-Thyroid-Lung syndrome: a patient with severe multi-system disorder due to a de novo mutation in the thyroid transcription factor 1 gene. Eur J Pediatr. 2005;164:28-30.

4. Patel NJ, Jankovic J. NKX2-1-Related Disorders In GeneReviews ${ }^{\oplus}$. Edited by Pagon RA, Adam MP, Ardinger HH, Bird TD, Dolan CR, Fong CT, Smith RJH, Stephens K. Seattle (WA): University of Washington, Seattle. 2014; 1993-2015.

5. Breedveld GJ, van Dongen JWF, Danesino C, Guala A, Percy AK, Dure LS, et al. Mutations in TITF-1 are associated with benign hereditary chorea. Hum Mol Genet. 2002;11(8):971-9.

6. Gruters A, Krude H, Biebermann H. Molecular genetic defects in congenital hypothyroidism. Eur J Endocrinol. 2004;151:U39-44.

7. Asmus F, Langseth A, Doherty E, Nestor T, Munz M, Gasser T, et al. Jerky Dystonia in children: spectrum of phenotypes and genetic testing. Mov Disord. 2009;24:702-9.

8. Doyle DA, Gonzalez I, Thomas B, Scavina M. Autosomal dominant transmission of congenital hypothyroidism, neonatal respiratory distress, and ataxia caused by a mutation of NKX2-1. J Pediatr. 2004;145:190-3.

9. Maquet E, Costagliola S, Parma J, Christophe-Hobertus C, Oligny LL, Fournet $\mathrm{JC}$, et al. Lethal respiratory failure and mild primary hypothyroidism in a term girl with a de novo heterozygous mutation in the TITF1/NKX2.1 gene. J Clin Endocrinol Metab. 2009;94(1):197-203.

10. Do Carmo Costa M, Costa C, Silva AP, Evangelista P, Santos L, Ferro A, et al. Nonsense mutation in TTF1 in a Portuguese family with benign hereditary chorea. Neurogenetics. 2005;6:209-15.

11. Gras D, Jonard L, Roze E, Chantot-Bastaraud S, Koht J, Motte J, et al. Benign hereditary chorea: phenotype, prognosis, therapeutic outcome and long term follow-up in a large series with new mutations in the TITF1/NKX2-1 gene. J Neurosurg Psychiatry. 2012;83:956-62.

12. Moya CM, Perez De Nanclares G, Castaño L, Potau N, Bilbao JR, Carrascosa A, et al. Functional study of a novel single deletion in the TITF1/NKX2.1 homeobox gene that produces congenital hypothyroidism and benign chorea but not pulmonary distress. J Clin Endocrinol Metab. 2006;91:1832-41.

13. Shetty VB, Kiraly-Borri C, Lamont P, Bikker H, Choong CSY. NKX2.1 mutations in brain-lung-thyroid syndrome: a case series of four patients. J Pediatr Endocrinol Metab 2013; doi:10.1515/jpem-2013-0109.

14. Guazzi S, Price M, De Felice M, Damante G, Mattei MG, Di Lauro R. Thyroid nuclear factor (TTF-1) contains a homeodomain and displays a novel DNA binding specificity. EMBO J. 1990;9:3631-9.

15. Kusakabe T, Kawaguchi A, Hoshi N, Kawaguchi R, Hoshi S, Kimura S. Thyroidspecific enhancer-binding protein/NKX2.1 is required for the maintenance of ordered architecture and function of the differentiated thyroid. Mol Endocrinol. 2006;20(8):1796-809.

16. Cao Y, Vo T, Millien G, Tagne JB, Kotton D, Mason RJ, et al. Epigenetic mechanisms modulate thyroid transcription factor 1-mediated transcription of the surfactant protein B gene. J Biol Chem. 2010;285(3):2152-64.

17. Guillot L, Carré A, Szinnai G, Castanet M, Tron E, Jaubert F, et al. NKX2-1 mutations leading to surfactant protein promoter dysregulation cause interstitial lung disease in "Brain-Lung-Thyroid Syndrome". Hum Mutat. 2010;31(2):E1146-62.

18. Inzelberg R, Weinberger M, Gak E. Benign hereditary chorea: An update. Parkinsonism Relat Disord. 2011;17:301-7.

19. Thorwarth A, Schnittert-Hubener S, Schrumpf P, Muller I, Jyrch S, Dame C, Biebermann H, Kleinau G, Katchanov J, Schulke M, Ebert G, Steininger A, Bonnemann C, Brockmann K, Christen H-J, Crock P, deZegher F, Griese M, 
Hewitt J, Ivarsson S, Hubner C, Kapelari K, Plecko B, Rating D, Stoeva I, Ropers H-H, Gruters A, Ullmann R, Krude H. Comprehensive genotyping and clinical characterisation reveal 27 novel Nkx2-1 mutations and expand the phenotypic spectrum J Med Genet Published Online First, April 2014. doi:10.1136/jmedgenet-2013-102248.

20. Barnett CP, Mencel JJ, Gecz J, Waters W, Kirwin SM, Vinette KMB, et al. Choreoathetosis, Congenital Hypothyroidism and Neonatal Respiratory Distress Syndrome With Intact NKX2-1. Am J Med Genet Part A. 2012;58A:3168-73.

21. Magno L, Catanzariti V, Nitsch R, Krude H, Naumann T. Ongoing expression of NKX2.1 in the postnatal mouse forebrain: potential for understanding NKX2.1 haploinsufficiency in humans? Brain Res. 2009;1304:164-86.

22. Peall K, Lumsden D, Kneen R, Madhu R, Peake D, Gibbon F, Lewis $H_{\text {, }}$ Hedderly T, Meyer E, Robb SA, Lynch B, King MD, Lin J-P, Morris HR, Jungbluth $\mathrm{H}$, Kurian MA. Benign hereditary chorea related to NKX2.1: expansion of the genotypic and phenotypic spectrum. Dev Med Child Neurol.2013, Oct 31. doi:10.1111/dmcn.12323.

23. Provenzano C, Veneziano L, Appleton R, Frontali M, Civitareale D. Functional characterization of a novel mutation in TITF-1 in a patient with benign hereditary chorea. J Neurol Sciences. 2008;264:56-62.

24. Hamvas A, Deterding RR, Wert SE, White FV, Dishop MK, Alfano DN, et al. Heterogeneous pulmonary phenotypes associated with mutations in the thyroid transcription factor gene NKX2-1. Chest. 2013;144(3):794-804.

25. Ferrara AM, De Michele G, Salvatore E, Di Maio L, Zampella E, Capuano S, et al. A novel NKX2.1 mutation in a family with hypothyroidism and benign hereditary chorea. Thyroid. 2008;18(9):1005-9.

26. Nakamura K, Sekijima Y, Nagamatsu K, Yoshida K, Ikeda S. A novel nonsense mutation in the TITF-1 gene in a Japanese family with benign hereditary chorea. J Neurol Sci. 2012;313:189-92.

27. Salerno T, Peca D, Meschini L, Schivino A, Petreschi F, Occasi F, et al. Respiratory Insufficiency in a Newborn With Congenital Hypothyroidism Due To a New Mutation of TTF-1/NKX2.1 Gene. Pediatr Pulmonol. 2014;49:E42-4.

\section{Submit your next manuscript to BioMed Central and take full advantage of:}

- Convenient online submission

- Thorough peer review

- No space constraints or color figure charges

- Immediate publication on acceptance

- Inclusion in PubMed, CAS, Scopus and Google Scholar

- Research which is freely available for redistribution 